\title{
Transcriptomic and Functional Analyses Reveal Roles of AcIR, a luxR-type Global Regular, in Regulating Motility and Virulence of Acidovorax citrulli
}

\author{
Wei Guan, ${ }^{1}$ Tielin Wang, ${ }^{2, \dagger}$ Qi Huang, ${ }^{3}$ Mei Zhao, ${ }^{4}$ Eryuan Tian, ${ }^{1}$ Yanfeng Liu, ${ }^{1}$ Bo Liu, ${ }^{1}$ Yuwen Yang, ${ }^{1}$ \\ and Tingchang Zhao ${ }^{1, \dagger}$ \\ ${ }^{1}$ State Key Laboratory for Biology of Plant Diseases and Insect Pests, Institute of Plant Protection, Chinese Academy of \\ Agricultural Sciences, Beijing, China \\ ${ }^{2}$ State Key Laboratory Breeding Base of Dao-di Herbs, National Resource Center for Chinese Materia Medica, China \\ Academy of Chinese Medical Sciences, Beijing, China \\ ${ }^{3}$ Floral and Nursery Plants Research Unit, U.S. Department of Agriculture, Agricultural Research Service, Beltsville, MD, \\ U.S.A. \\ ${ }^{4}$ Department of Plant Pathology, University of Georgia, Tifton, GA, U.S.A.
}

Accepted 26 March 2021.

LuxR-type transcriptional regulators are essential for many physiological processes in bacteria, including pathogenesis. Acidovorax citrulli is a seedborne bacterial pathogen responsible for bacterial fruit blotch, which causes great losses in melon and watermelon worldwide. However, the LuxR-type transcriptional factors in $A$. citrulli have not been well studied, except for the previously reported LuxR-type regulatory protein, AcrR, involved in regulating virulence and motility. Here, we characterized a second LuxR-type regulator, AclR, in the group II strain Aac-5 of A. citrulli by mutagenesis, virulence and motility assays, and transcriptomic analysis. Deletion of $a c l R$ resulted in impaired twitching and swimming motility and flagellar formation and diminished virulence but increased biofilm formation. Transcriptomic analysis revealed that 1,379 genes were differentially expressed in the aclR mutant strain, including 29 genes involved in flagellar assembly and 3 involved in pili formation, suggesting a regulatory role for AclR in multiple important biological functions of $A$. citrulli. Together, our results not only indicate that AclR plays a global role in transcriptional regulation in $A$. citrulli influencing motility, biofilm formation, and virulence

\section{${ }^{\dagger}$ Corresponding authors: T. Wang; wt182@163.com; and T. Zhao; zhaotgcg@163.com}

Funding: This work was supported financially by the Key Project at Central Government Level: Capacity building for sustainable use of valuable Chinese medicinal resources (2060302), the National Natural Science Foundation of China (31701754), the National Key Research and Development Program of China (2016YFD0201004 and 2018YFD0201302), the Agricultural Science and Technology Innovation Program of the Chinese Academy of Agricultural Sciences (CAAS-ASTIP), and the China earmarked fund for Modern Agroindustry Technology Research System (CARS-26)

*The $\boldsymbol{e}$-Xtra logo stands for "electronic extra" and indicates that supplementary tables and supplementary figures are published online.

The author(s) declare no conflict of interest.

(c) (1) $(\Theta)$ Copyright (๑) 2021 The Author(s). This is an open access article distributed under the CC BY-NC-ND 4.0 International license. but also provide perspective regarding the regulatory network of biological functions in $A$. citrulli.

Keywords: Acidovorax citrulli, AclR, bacterial fruit blotch, LuxR

Transcriptional factors of the LuxR family have been widely studied and identified in a wide range of bacteria, where they can stimulate or repress the expression of various genes. They are involved in important physiological processes, including bioluminescence, quorum sensing (QS), motility, biofilm formation, and pathogenesis (Ball et al. 2017; Tsai and Winans 2010; van Kessel et al. 2013). LuxR-type transcriptional regulators contain a characteristic structure that is composed of a helix-turn-helix at the carboxyl terminal for binding promoters (Fuqua et al. 1996; Patankar and González 2009) and a variable domain at the amino terminal that interacts with signals such as QS and two-component signal transduction (Chen and Xie 2011; Patankar and González 2009; Santos et al. 2012). LuxR family proteins were first described and are best known for their important role in QS, in which they function as signal receptors and transcriptional regulators paired with the autoinducer synthase protein LuxI (Fuqua and Greenberg 2002; Guan et al. 2020). In addition to luxR, which is associated with luxI, several $\operatorname{luxR}$ homologs that are not paired with luxI have been found to regulate virulence factors, biofilm formation, and host immune responses (Fuqua et al. 2001; Santos et al. 2012). Notably, a LuxR homolog in Salmonella enterica regulates the flagellar master regulatory complex $\mathrm{FlhD}_{4} \mathrm{C}_{2}$ in flagellar assembly which, in turn, affects flagellar formation (Singer et al. 2013).

Bacterial fruit blotch (BFB) of cucurbits is a serious threat to the cucurbit industry. The causal agent of BFB is Acidovorax citrulli, a Gram-negative, seedborne bacterium with a single polar flagellum (Bahar and Burdman 2010). Based on phenotypical and genomic sequence characteristics, A. citrulli strains have been divided into at least two distinct groups. Group I strains are isolated mainly from nonwatermelon hosts, while group II strains are isolated mainly from watermelon and are highly virulent to watermelon (Burdman et al. 2005; Chen et al. 2009; Walcott et al. 2004; Yan et al. 2013). Like other plantpathogenic bacteria, A. citrulli relies on QS for communication 
and to colonize host plants. Elimination of key genes in the QS system, luxI/luxR and aacI/aacR in group I and group II A. citrulli strains, respectively, abolished acyl-homoserine lactone production and, in turn, led to reduced virulence, swimming and twitching motility, and seed-to-seedling transmission (Chen et al. 2009; Fan et al. 2011; Johnson and Walcott 2013; Wang et al. 2016). These results unveiled the crucial role that $l u x R$ and $a a c R$ play in the pathogenesis of $A$. citrulli in melon and watermelon.

LuxR-type transcriptional regulators that do not have a classic autoinducer domain are widespread in bacteria. For example, there are 23 LuxR-type genes without autoinducer in the chromosome of Pseudomonas chlororaphis, and one of them, pcsR2, plays an important role in regulating phenazine production (Pan et al. 2020). Similar to other bacteria that contain LuxR homologs involved in many important biological functions, $A$. citrulli strain Aac-5 was found to harbor many other transcriptional regulators belonging to the LuxR family in addition to luxR and aacR in its genome (Guan et al. 2020). Of these LuxR homologs, AcrR was found to regulate flagellar assembly and contribute to virulence, biofilm formation, and motility (Guan et al. 2020). In the present study, we identified another LuxR family transcriptional regulator, AclR, in the group II A. citrulli strain Aac-5 by mutational and transcriptomic analyses, and found that AclR functions as a global transcriptional regulator, especially for motility, through mechanisms that differ from those of AcrR in A. citrulli.

\section{RESULTS}

AclR is a putative LuxR family transcriptional regulator.

We identified an open reading frame (ORF) encoding a 210amino-acid protein in the genome sequence of $A$. citrulli group II strain AAC00-1 (GenBank accession number CP000512.1), with the locus tag Aave_3862 located at nucleotides 4,288,292 to $4,288,924$. The protein contained a response regulatory domain at the $\mathrm{N}$ terminus and an HTH LuxR-type DNA-binding domain at the $\mathrm{C}$ terminus. A BLASTp search showed that the ORF shared $100 \%$ amino acid sequence identity with protein WP_011796894.1 in A. citrulli strains, and 99\% identity with protein WP_013596140.1 in Acidovorax spp., annotated as a response regulator transcription factor. AclR was found to have no significant similarity with the QS signal receptor AacR (ABM34355.1) (Wang et al. 2016) and 48\% similarity with AcrR (ABM34922.1) (Guan et al. 2020) in the A. citrulli genome when the BLASTp suite in the NCBI database was used. Thus, we designated the ORF as AclR (Acidovorax citrulli LuxR-type regulator) in A. citrulli.

Construction of the $a c l R$ mutant strain $\Delta a c l R$ was confirmed by PCR amplification of strain $\Delta a c l R$ using LaclR-F and RaclR$\mathrm{R}$ primers (Table 1), and through the subsequent sequencing of the PCR product. The product was $1,960 \mathrm{bp}$ in size and contained 550-bp upstream and 555-bp downstream fragments, separated by an 855-bp gentamicin (Gm) cassette, which replaced the 633bp aclR gene in the wild-type strain Aac-5 (data not shown).

Successful construction of the complementation strain $\Delta a c l R-c$ was confirmed by the resistance of $\Delta a c l R-c$ to kanamycin $(\mathrm{Km})$, because $\Delta a c l R-c$ harbored the plasmid pBBR-aclR (Table 2). The presence of pBBR-aclR was verified by PCR amplification of the strain $\Delta a c l R-c$ using the primers aclR-F and aclRR. Sequencing confirmed that the PCR product was the 633bp aclR gene.

\section{The virulence of $A$. citrulli decreased in the absence of $a c l R$.}

To assess the effect of AclR on the virulence of $A$. citrulli strain Aac-5, watermelon seedlings were inoculated with a cell suspension of wild-type strain $A a c-5$, $a c l R$ mutant strain $\Delta a c l R$, and its complemented strain $\Delta a c l R-c$. Ten days after inoculation, most leaves of seedlings inoculated with the wild-type and complementation strains showed typical symptoms of BFB: darkgreen, water-soaked lesions. Few leaves of the seedlings inoculated with $\Delta a c l R$ presented BFB symptoms, while no symptoms were observed in seedlings inoculated with sterile water (Fig. 1A). The disease index (DI) of the wild-type strain was 48.88 , which was significantly higher than that of the $\Delta a c l R$ strain (DI = 29.01), and was similar to that of the complementation strain $\Delta a c l R-c(\mathrm{DI}=42.09)$ (Fig. 1B).

In planta growth ability was determined in the cotyledons of watermelon seedlings. Bacterial cell suspensions of the wild-type strain Aac-5, the mutant strain $\Delta a c l R$, and the complementation strain $\Delta a c l R-c$ were each injected into watermelon cotyledons, and sterile water was used as a negative control. No symptoms were observed at the injection site on cotyledons 1 and $24 \mathrm{~h}$ after inoculation (hai), whereas water-soaked necrosis was observed around the injection site at 48 hai. Lesion development began at 72 and 96 hai in cotyledons inoculated with the wild-type and complementation strains, respectively, but not in those inoculated with the mutant strain (Fig. 1C). Quantitative assessment of the in planta bacterial growth assay found no significant difference in the populations of the wild-type, mutant, and complementation strains until $72 \mathrm{~h}$, when the population of the mutant strain was significantly smaller than that of the wild-type strain Aac-5 (Fig. 1D).

\section{The $\Delta a c l R$ strain increased biofilm formation but remained similar in growth ability compared with its wild-type strain Aac-5.}

After 7 days of incubation, crystal violet staining revealed the formation of a visible ring by $\Delta a c l R$ on the inner wall of the flask, whereas no such ring was observed for the wild-type and complementation strains (Fig. 2A). This observation was confirmed by the quantitative biofilm assay, in which the mean absorption of the biofilm for $\Delta a c l R$ was 2.09. Conversely, the absorption value for the wild-type Aac-5 and complementation strains was 0 (Fig. 2E). Our results showed that mutation of the aclR gene altered $A$. citrulli biofilm formation.

In order to investigate whether the effect of gene $a c l R$ on the virulence and biofilm formation was due to growth ability of the $\triangle a c l R$ mutant, we determined growth curves of Aac-5, $\Delta a c l R$, and its complementation strain $\Delta a c l R-c$ by measuring the optical density of bacterial cell suspensions incubated in King's B (KB)

Table 1. Primers used for the construction of mutant and complemented strains

\begin{tabular}{|c|c|c|c|}
\hline Primer & Sequence $\left(5^{\prime}-3^{\prime}\right.$, restriction enzyme sites are underlined) & Restriction enzyme & Product of PCR \\
\hline LaclR-F & GAATTCGAAGTCGAGGCCGTAGGTG & EcoRI & $550 \mathrm{bp}$ \\
\hline LaclR-R & $\overline{\text { GGATCCTCGCCGGCTGTGGAAAG }}$ & BamHI & \\
\hline RaclR-F & GTCGACTGAGAGTTTCTTTCAAAG & SalI & $555 \mathrm{bp}$ \\
\hline RaclR-R & AAGCTTCATGCGTCGTCGTTGTT & HindIII & \\
\hline aclR-F & CGGGATCCTCAATCGATCAGCTTT & BamHI & $633 \mathrm{bp}$ \\
\hline aclR-R & CCCAAGCTTATGATCAAGATCGGCA & HindIII & \\
\hline $\mathrm{GmF}$ & GGATCCCGACGCACACCGTGGAAA & BamHI & $855 \mathrm{bp}$ \\
\hline GmR & GTCGACGCGGCGTTGTGACAATTT & SalI & \\
\hline
\end{tabular}


broth at $28^{\circ} \mathrm{C}$. The mutant strain $\Delta a c l R$ showed optical density similar to its wild-type strain Aac-5 (calculated by Student's $t$ test, $P>0.05$ ) (Supplementary Fig. S1).

\section{Abolition of twitching and swimming motility in the $\Delta a c l R$ strain.}

Colonies of the A. citrulli strains were observed under a microscope to assess the formation of corrugated trajectories or halos, indicating the migration of each bacterial strain via twitching motility. The wild-type strain Aac-5 produced typical halos, which were corrugated with several layers of fringed margins, whereas the mutant $\Delta a c l R$ and complementation $\Delta a c l R-c$ strains produced smooth halos around their colonies (Fig. 2B). These results demonstrated that twitching function was impaired in A. citrulli following the loss of the aclR gene.

To assess the effect of $a c l R$ on the swimming motility of A. citrulli strains, a swimming assay was performed on semisolid agar plates. The results revealed that the mutant strain did not spread 36 hai, whereas the wild-type Aac-5 and complementation $\Delta a c l R-c$ strains spread to approximately one-quarter of the Petri dish (Fig. 2C), indicating that swimming ability was restored in the complementation strain. When the bacterial suspension was placed on the basal medium plate, the average diameter of the drops was $1.01 \mathrm{~cm}$. At 36 hai at $28^{\circ} \mathrm{C}$, the wildtype strain Aac-5 formed bacterial lawns with an average diameter of $2.97 \mathrm{~cm}$, which was significantly larger than that formed by the mutant strain $\Delta a c l R$, with an average diameter of $1.26 \mathrm{~cm}$. Conversely, the complementation strain $\Delta a c l R-c$ formed bacterial lawns with an average diameter of 2.90, which was similar to that observed for the wild-type strain. This indicated that swimming motility was lost in the Aac-5 strain following loss of the $a c l R$ gene, and was subsequently restored when the $a c l R$ gene was complemented (Fig. 2F).

To investigate the mechanism underlying the loss of swimming motility, we observed the flagellar formation of $A$. citrulli strains by transmission electron microscopy. The wild-type and complemented strains were found to form an intact polar flagellum, whereas no flagella were observed in all examined micrographs of the mutant strain (Fig. 2D).

\section{Significant changes in the expression of genes related to biofilm, twitching, and swimming in A. citrulli $\Delta a c l R$ compared with the wild-type strain Aac-5.}

To confirm the regulatory role of $a c l R$ in biofilm formation, twitching, and swimming motility, the gene expression of $\Delta a c l R$ was compared with that of the wild-type strain Aac-5 via transcriptome and gene ontology (GO) analyses. The RNA sequencing (RNA-seq) results showed that 1,379 genes were differentially expressed in $\triangle a c l R$ compared with Aac-5, including 638 highly and 741 lowly expressed genes (Supplementary Table S1). Some of the genes are also differentially expressed in the $\Delta a c r R$ mutant (Supplementary Table S1). The sequencing results were validated using reverse-transcription quantitative PCR (RT-qPCR) with primer sets for 10 selected genes (Supplementary Fig. S2).

The differentially expressed genes (DEGs) were divided into three main categories-biological process, molecular function, and cellular component-according to the GO analysis. GOs with significant enrichment related to bacterial-type flagellar motility were the only differentiating functions that were downregulated in $\triangle a c l R$ compared with the wild-type strain Aac-5. These included the subcategories motor activity, cell projection part, bacterial-type flagellum part, bacterial flagellum, ciliary or bacterial-type flagellar motility, localization of cell, cell motility, cellular component movement, and locomotion (Fig. 3A). Additionally, highly expressed genes significantly affected the GO terms involved in the purine nucleotide cycle, protein metabolic process, phosphorus metabolic process, and carbohydrate metabolic process (Fig. 3B). GO enrichment of the lowly expressed genes was focused on assembly of the bacterial flagellum, suggesting that deletion of the $a c l R$ gene positively affected flagellum formation and motility of the A. citrulli Aac-5 strain.

To compare the genes affected by $a c l R$ and $a c r R$, a Venn diagram was generated based on the transcriptome data of $a c l R$ and acrR mutant strains. The two strains shared 240 DEGs, while 1,139 and 154 DEGs were unique to $\Delta a c l R$ and $\Delta a c r R$, respectively (Supplementary Fig. S3).

To elucidate the role of AclR in signaling pathways in A. citrulli Aac-5, Kyoto Encyclopedia of Genes and Genomes (KEGG) pathways were analyzed based on the RNA-seq results. The results revealed that genes involved in oxidative phosphorylation, lipopolysaccharide biosynthesis, and amino sugar and nucleotide sugar metabolism were significantly highly expressed compared with levels in the wild-type strain Aac-5 (Fig. 4A). Conversely, the expression of genes involved in starch and sucrose metabolism, inositol phosphate metabolism, and glyoxylate and dicarboxylate metabolism was lower in $\Delta a c l R$ than in Aac-5 (Fig. 4B). In addition to these pathways in the enrichment assay, 29 DEGs involved in flagellar assembly were expressed at lower levels in $\Delta a c l R$ compared with the wild-type strain Aac-5, in addition to three piliassociated genes. In all, 10 of 11 DEGs involved in chemotaxis

Table 2. Bacterial strains and plasmids used in this study

\begin{tabular}{|c|c|c|}
\hline Strain or plasmid & Description $^{a}$ & Reference or source \\
\hline \multicolumn{3}{|l|}{ Strain } \\
\hline \multicolumn{3}{|l|}{ Escherichia coil } \\
\hline DH5 $\alpha$ & $\begin{array}{l}\text { supE44 DlacU169( } \Phi 80 l a c Z \text { D M15) hsdR17 } \\
\text { recA1 endA1 gyrA96 thi-1 relA1 }\end{array}$ & Hanahan 1983 \\
\hline \multicolumn{3}{|l|}{ Acidovorax citrulli } \\
\hline Aac-5 & Wild-type watermelon strain; $A p^{r}$ & Yan et al. 2013 \\
\hline$\Delta a c l R$ & aclR mutant, $\mathrm{Ap}^{\mathrm{r}} ; \mathrm{Gm}^{\mathrm{r}}$ & This study \\
\hline$\Delta a c l R-c$ & $\begin{array}{l}\Delta a c l R \text { complementation strain, } \Delta a c r R \\
\quad \text { containing pBBR-acrR; } \mathrm{Ap}^{\mathrm{r}}, \mathrm{Gm}^{\mathrm{r}}, \mathrm{Km}^{\mathrm{r}}\end{array}$ & This study \\
\hline \multicolumn{3}{|c|}{ 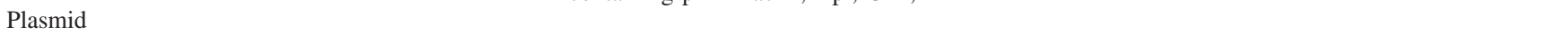 } \\
\hline pK18mobsacB & $\begin{array}{l}\text { Cloning and suicide vector with a } s a c B \text { gene for } \\
\text { mutagenesis; } \mathrm{Km}^{\mathrm{r}}\end{array}$ & Schäfer et al. 1994 \\
\hline pK18-aclRGm & $\begin{array}{l}\text { pK18mobsacB carrying } 633 \text {-bp coding region of } \\
\text { the acrR gene replaced by } 855-\mathrm{bp} \mathrm{Gm} \\
\text { cassette, as well as 550- and 555-bp upstream } \\
\text { and downstream sequences of the gene; } \mathrm{Km}^{\mathrm{r}}\end{array}$ & This study \\
\hline pBBR1MCS-2 & Broad-host range expression vector; $\mathrm{Km}^{\mathrm{r}}$ & Kovach et al. 1995 \\
\hline pBBR-aclR & $\begin{array}{l}\text { pBBR1MCS-2 carrying 633-bp coding region of } \\
\text { the } a c l R \text { gene; } \mathrm{Km}^{\mathrm{r}}\end{array}$ & This study \\
\hline
\end{tabular}

${ }^{\mathrm{a}} \mathrm{Km}^{\mathrm{r}}, \mathrm{Ap}^{\mathrm{r}}$, and $\mathrm{Gm}^{\mathrm{r}}$ indicate resistance to kanamycin, ampicillin, and gentamycin, respectively. 
were downregulated, indicating that the low expression of genes related to flagellar assembly and chemotaxis in $\Delta a c l R$ may lead to the loss of motility, suggesting a regulatory role for AclR in the motility of A. citrulli Aac-5 (Table 3).

\section{DISCUSSION}

LuxR family transcriptional regulators have been found to be involved in various critical biological functions in bacteria. However, knowledge of the functions of LuxR-type regulators in $A$. citrulli remains limited. In this study, we identified a LuxR-type transcriptional regulator, AclR, which contributes to virulence, biofilm formation, swimming, and twitching motility, as well as the formation of polar flagella in the A. citrulli Aac-5 strain. Additionally, transcriptomic analysis revealed that, compared with the wild-type strain Aac-5, 1,379 genes were differentially expressed in the $a c l R$ mutant strain, including 29 DEGs involved in flagellar assembly and 3 involved in pili formation, indicating a regulatory role for AclR in A. citrulli motility.

Twitching is a method of motility that enables bacteria to move across surfaces, and is conferred by type IV pili (T4P), the filamentous appendages of bacteria (Nieto et al. 2019; Talà et al. 2019). A. citrulli strains in which twitching ability was lost presented reduced virulence compared with strains in which twitching was present, indicating that twitching is required for the full virulence of $A$. citrulli (Bahar et al. 2009). In the present study, when the $a c l R$ gene was eliminated, twitching motility was abolished in A citrulli strain Aac-5, and virulence toward watermelon seedlings and cotyledons was reduced. This is consistent with previous results showing that the $A a c-5$ strain of $A$. citrulli lost twitching motility and had reduced virulence when a
A

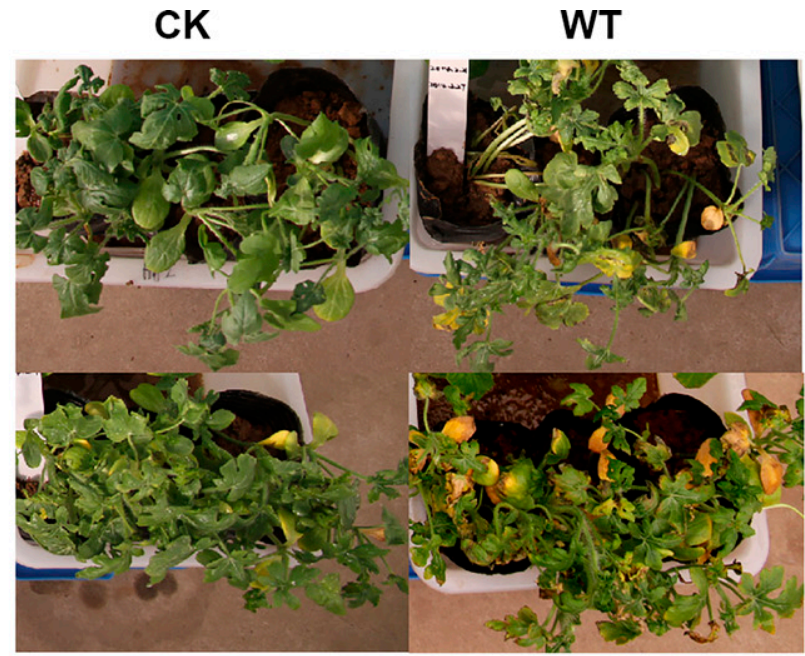

$\Delta a c I R$
B

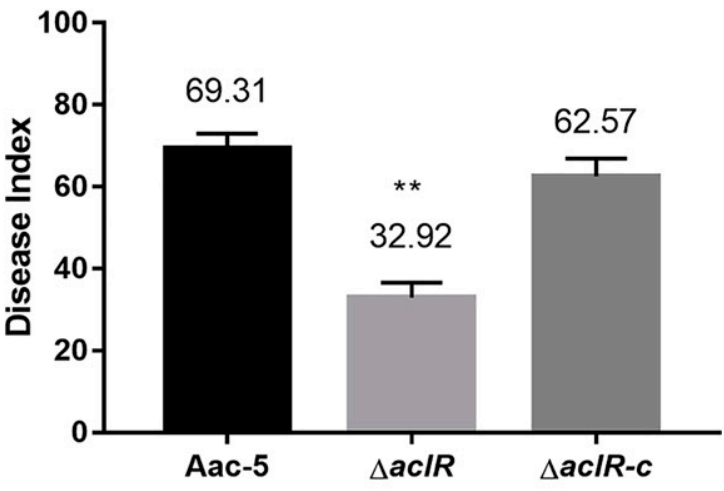

Acidovorax citrulli strains
C

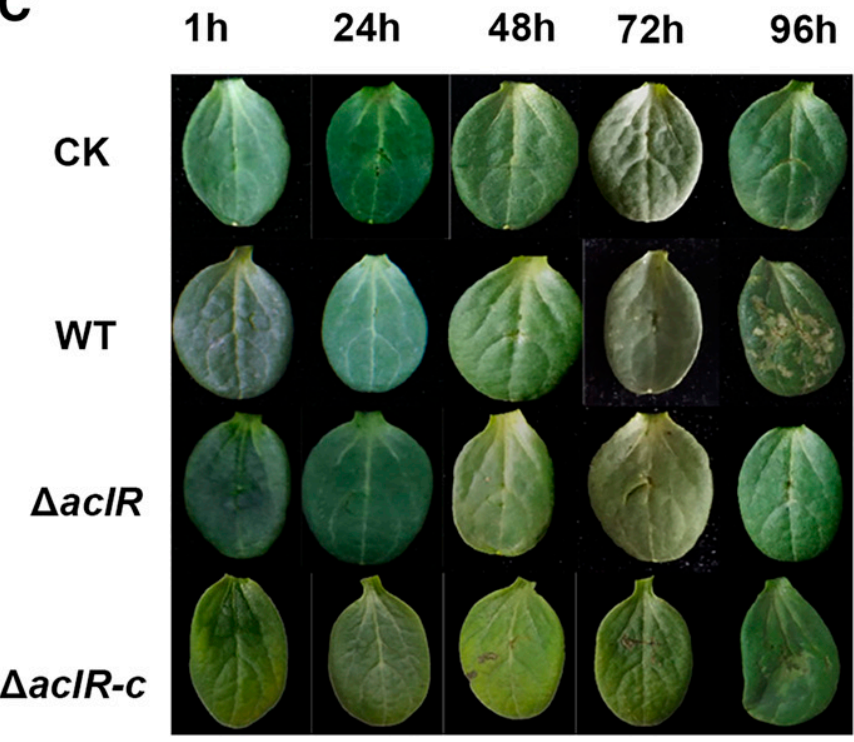

D

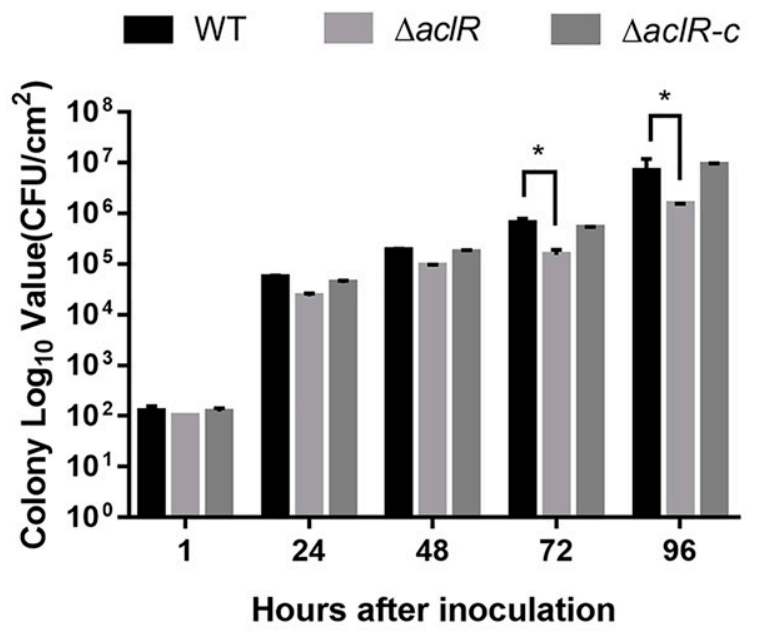

Fig. 1. Effect of aclR on the virulence of Acidovorax citrulli toward watermelon leaves. A, Appearance of watermelon seedlings 10 days after inoculation with sterile water (CK), the wild-type (WT) strain Aac-5, the aclR deletion mutant $\Delta a c l R$, and the complementation strain $\Delta a c l R$ - $c$ of Acidovorax citrulli. B, Quantitative assessment of the virulence of A. citrulli strains 10 days after inoculation based on a disease index of 0 to 100 . Bars represent the standard errors of the means from three experiments, each containing six inoculated watermelon seedlings in three pots per strain. $\mathbf{C}$, Watermelon cotyledons inoculated with CK, the WT strain Aac-5, the aclR deletion mutant strain $\Delta a c l R$, and the mutant complementation strain $\Delta a c l R$-c of A. citrulli strains at 1, 24, 48, 72, and $96 \mathrm{~h}$ after inoculation (hai). D, Number of colonies isolated from leaf disks of watermelon cotyledons inoculated with the WT, $\Delta a c l R$, and $\Delta a c l R-c$ strains at 1,24, 48, 72, and 96 hai. Bars represent the standard errors of the means from three experiments, each containing six cotyledon discs per strain per time point. Asterisks indicate a significant difference compared with the WT strain, calculated by Student's $t$ test $(P<0.05)$. 
LuxR-type transcriptional regulator AcrR was eliminated (Guan et al. 2020). Additionally, our transcriptome analysis showed that expression of the pilQ, pilV, and pilN genes was significantly lower in the $\Delta a c l R$ strain than in the wild-type Aac-5 strain of $A$. citrulli. PilQ is a member of the secretin family of outer membrane proteins and is essential for T4P biosynthesis. It forms complexes in the membrane fraction, through which the pilus structures and the DNA translocator are thought to be extruded (Burkhardt et al. 2011; Narulita et al. 2016). PilV is an adhesion protein involved in the formation of minor pilins (Giltner et al. 2010; Li and Li 2014). PilN, together with PilM, PilN, PilO, and PilP, forms an inner-membrane subcomplex potentially involved in the alignment of secretin with the pilus assembly machinery (Ayers et al. 2009; Tammam et al. 2011). Attenuated expression of the pilQ, pilV, and pilN genes in the aclR mutant strain Aac-5 may lead to the loss of twitching motility in A. citrulli.

An intact flagellum is required for the full virulence of group I and II strains of A. citrulli (Bahar et al. 2011). A. citrulli strains failed to form an intact flagellum and presented decreased virulence when the $\mathrm{fliC}$ gene was deleted (Bahar et al. 2011; Zhang et al. 2017). Deletion of a transcriptional regulator could lead to a failure of flagella formation in the A. citrulli Aac-5 strain and, in turn, lead to a decrease in virulence in watermelon seedlings (Guan et al. 2020). In the present study, we generated an $a c l R$ deletion mutant of Aac-5, and found that the virulence of the mutant strain was decreased followed seedling inoculation and in planta growth assays. This is consistent with previous studies, indicating that flagella play a critical role in the virulence of A. citrulli.

Flagella assembly is a hierarchical process involving approximately 50 genes, the expression of which is tightly regulated (Subramanian and Kearns 2019). Previously, we showed that the LuxR-type regulator AcrR regulated the assembly of flagella in A. citrulli Aac-5, and also contributed to virulence and biofilm formation. In total, 33 genes associated with flagellum assembly in the $a c r R$ mutant strain were found to be differentially expressed compared with the wild-type strain Aac-5, including 3 highly expressed genes $(f i P, f l i Q$, and $f i R)$ which reside within the MS-ring and are anchored at the cell membrane (Guan et al. 2020). In the present study, transcriptomic analysis revealed that 29 genes related to flagellum assembly were expressed at low levels in the $a c l R$ mutant strain, whereas $f i P, f i Q$, and $f i R$ were not found to be differentially expressed. This indicated that the regulatory mechanism of aclR differs from that of acrR in A. citrulli Aac-5. Genes fliP, fliQ, and fliR may be regulated by other factors when $a c l R$ or $a c r R$ is absent. Because the MS-ring is thought to be formed during the earliest stage of flagellar assembly (Macnab 2003), we speculated that acrR and aclR may regulate flagellar assembly in A. citrulli through different mechanisms.

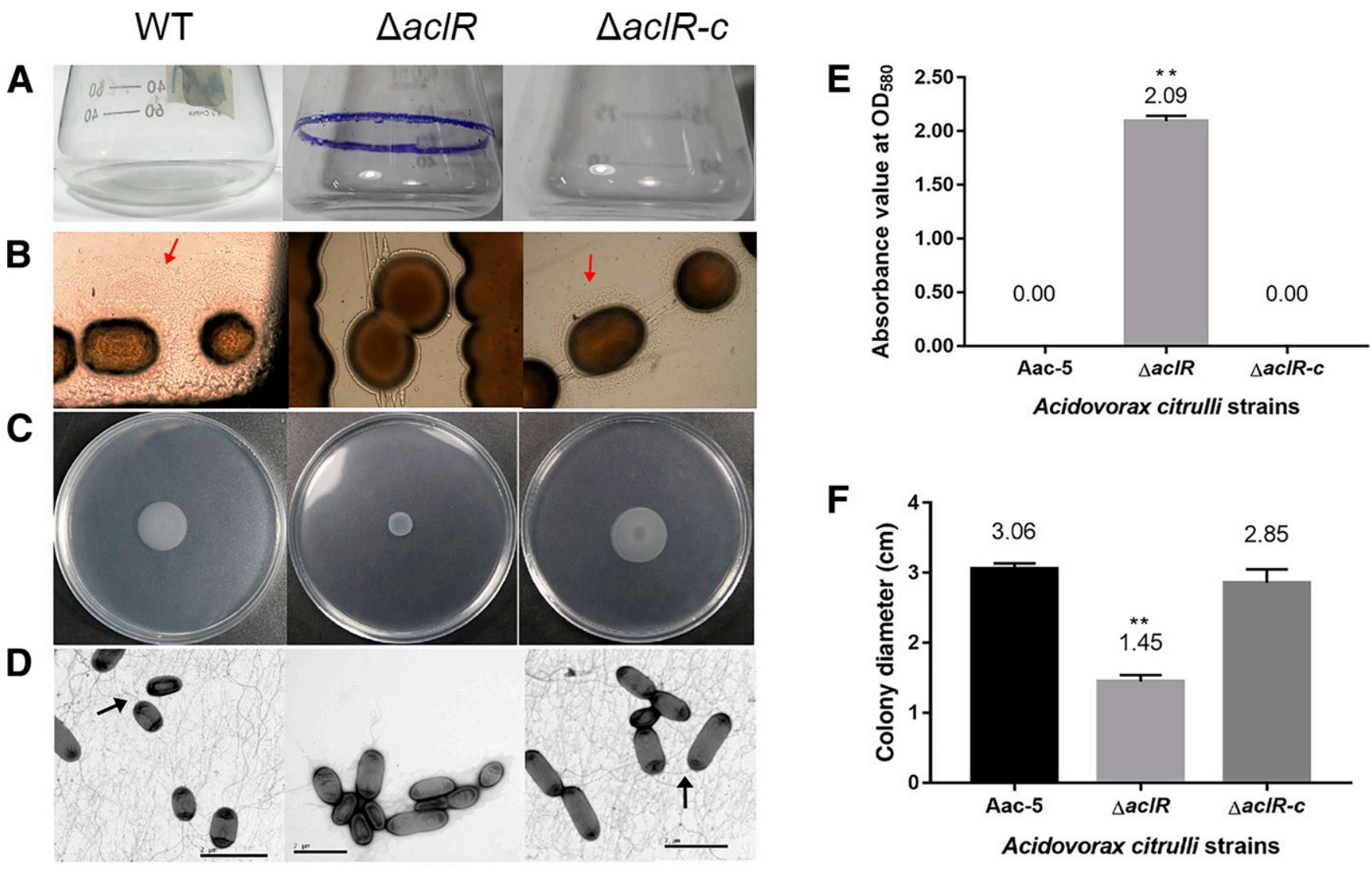

Fig. 2. Effect of $a c l R$ on biofilm formation and motility in Acidovorax citrulli Aac-5. WT = wild-type strain Aac-5 of $A$. citrulli, $\Delta a c l R=$ aclR deletion mutant strain of Aac-5, and $\Delta a c l R-c=$ complementation strain of $\Delta a c l R$. A and $\mathbf{E}$, Effect of $a c l R$ on biofilm formation in A. citrulli. Biofilm formation of $A$. citrulli strains is visualized by a violet ring formed on the inner surface of the glass flasks (A). The stained biofilm was quantitively analyzed by measuring the optical density at $580 \mathrm{~nm}\left(\mathrm{OD}_{580}\right)$. Error bars represent the standard errors of the means from the experiments, each containing three replicates per treatment $(\mathrm{E})$. B, Effect of $a c l R$ on the twitching motility in A. citrulli. The WT strain Aac-5 and the complementation strain $\Delta a c l R$ - $c$ produced typical corrugated halos around bacterial colonies (red arrows), indicating bacterial motility via twitching. The mutant strain $\Delta a c r R$ produced smooth halos. $\mathbf{C}$ and $\mathbf{F}$, Effect of aclR on the swimming motility of A. citrulli. Swimming motility of A. citrulli strains $36 \mathrm{~h}$ after inoculation of $10 \mu \mathrm{l}$ of each bacterial suspension to the center of a soft basal medium plate incubated at $28^{\circ} \mathrm{C}(\mathrm{C})$ and diameter of colonies of each strain on the basal medium plate (F). D, Effect of $a c l R$ on flagellum formation in A. citrulli. Intact polar flagellums were observed in the WT and $\Delta a c l R$ - $c$ strains (black arrows), while the $\Delta a c l R$ formed a short and fragile flagellum. Bars in the figures represent the standard errors of the means from three experiments, and each experiment contained three replicates per strain. Asterisks $\left(^{* *}\right)$ indicate $P<0.01$ by Student's $t$ test. 
Bacteria are held together by an extracellular matrix, forming multicellular aggregates, called a biofilm. Biofilms play a critical role in many life stages of bacteria, including adhesion to surfaces, resistance to the environment, and virulence to hosts
(Danhorn and Fuqua 2007; Vuong et al. 2004). The bacterial cells in the aggregates are nonmotile (Lemon et al. 2007); thus, it is assumed that a motility-biofilm transition occurs during which inhibited motility promotes biofilm formation (Guttenplan and

A

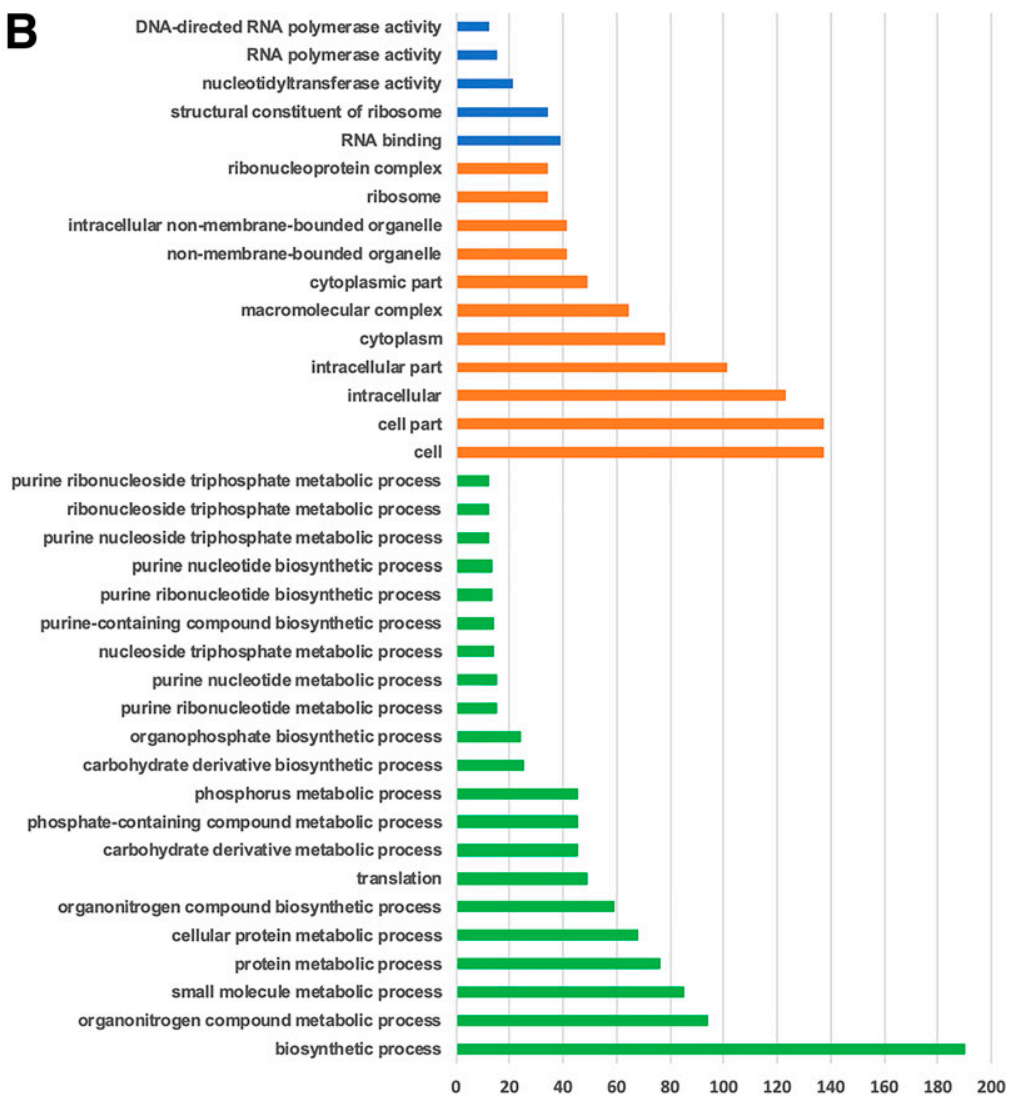

Fig. 3. Gene ontology of A, lowly and $\mathbf{B}$, highly differentially expressed genes between aclR mutant and wild-type strains of Acidovorax citrulli. The y axis indicates the gene ontology terms, which are divided into three categories: biological processes indicated in green, molecular functions in blue, and cellular components in orange. The $\mathrm{x}$ axis represents the number of genes.

A

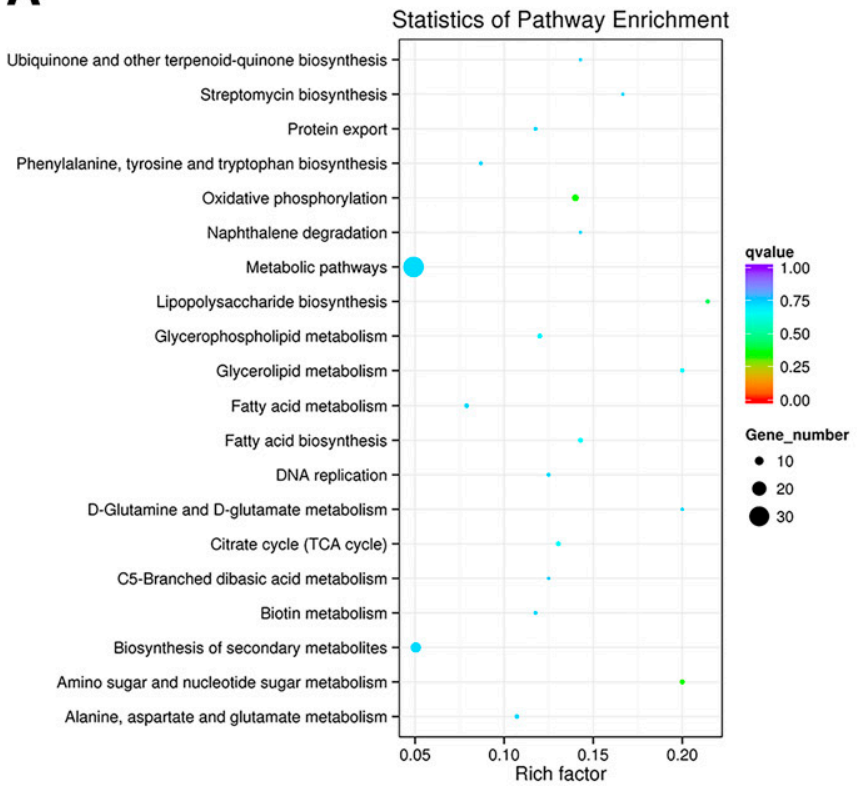

B

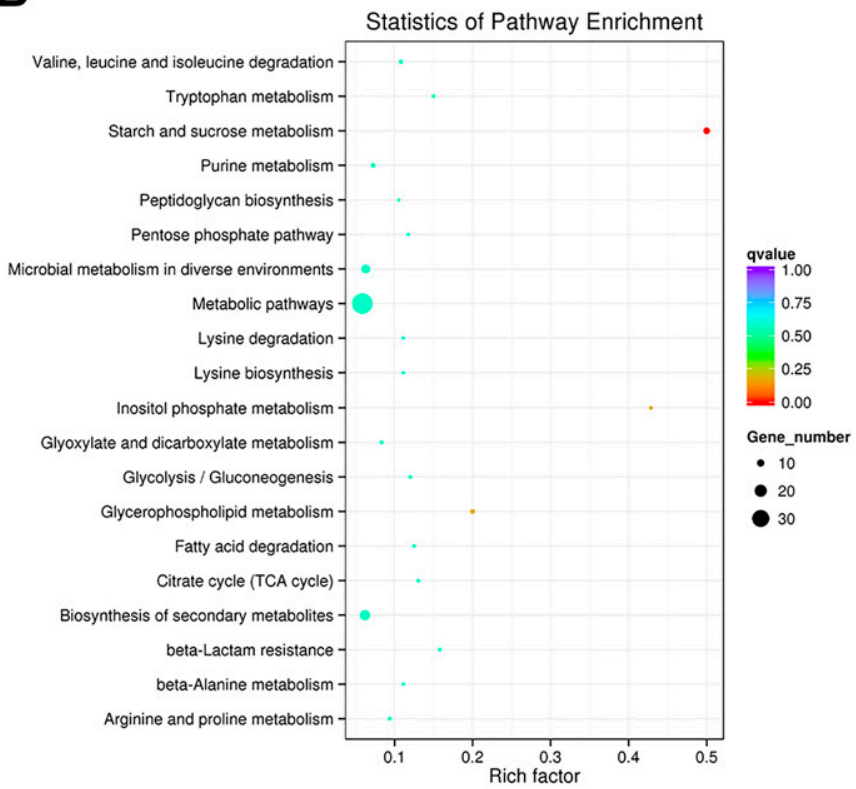

Fig. 4. Functional classification and enrichment of A, highly and $\mathbf{B}$, lowly expressed genes between the aclR mutant and wild-type strains of Acidovorax citrulli. Kyoto Encyclopedia of Genes and Genomes (KEGG) pathway enrichment bubble plot of differentially expressed genes (DEGs) in $\Delta a c l R$ compared with the wild-type strain Aac-5 of A. citrulli. The size of the bubbles represents different numbers of DEGs, and the ordinate represents different KEGG classifications. 
Kearns 2013). In both Gram-positive and -negative bacteria, regulatory genes regulate the motility-biofilm transition. EpsE inhibits flagellar motility in the Gram-positive bacterium Bacillus subtilis, and its mutation results in a severe defect in biofilm formation (Guttenplan et al. 2010). In the Gram-negative bacterium $P$. aeruginosa, the transcriptional regulator FleQ activates flagellar genes and represses genes involved in biofilm formation (Hickman and Harwood 2008). In Vibrio cholerae, HapR, which is homologous to the QS regulator LuxR, promotes motility and represses the expression of genes involved in biofilm formation at high cell densities (Waters et al. 2008; Yildiz et al. 2004). The absence of HapR was shown to increase biofilm formation and decrease motility (Zhu and Mekalanos 2003; Zhu et al. 2002). In A. citrulli, the wild-type strain Aac-5, along with another group II strain, W1, were unable to form a biofilm but could form a polar flagellum and maintain motility when cultured in either nutrition broth or KB medium (Bahar et al. 2011; Wang et al. 2016). Similar to HapR in $V$. cholerae, a LuxR-type regulator, AcrR, in A. citrulli was found to positively regulate flagellum assembly and negatively regulate biofilm formation (Guan et al. 2020). In the present study, the expression of genes involved in flagellum assembly and pili formation were downregulated when $a c l R$ was absent in the Aac-5 strain of A. citrulli. This, in turn, resulted in the loss of flagellum and reduced motility, leading to increased biofilm formation, suggesting a crucial role for the LuxR family regulators in regulating the motility-biofilm transition.

An interesting finding in our study is that A. citrulli harbors two LuxR-type regulators that regulate similar phenotypes such as virulence and motility. However, this phenomenon is not limited to A. citrulli, and has also been found in other pathogenic bacteria. VjbR and BlxR are LuxR-type regulators in bacterial

Table 3. Relative expression of genes involved in flagellum and pilus assembly

\begin{tabular}{|c|c|c|c|c|}
\hline Gene ID & Product & $\begin{array}{c}\log _{2} \\
\text { (fold-change) }\end{array}$ & $P$ adj & $\begin{array}{c}\text { Regulated } \\
\text { by } a c r R\end{array}$ \\
\hline Aave_4386 & FliO & -1.7084 & $6.23 \mathrm{E}-04$ & - \\
\hline Aave_4387 & FliN & -1.4168 & $2.36 \mathrm{E}-03$ & + \\
\hline Aave_4388 & FliM & -1.4063 & $2.05 \mathrm{E}-03$ & - \\
\hline Aave_4390 & FliK & -2.1997 & $5.35 \mathrm{E}-07$ & + \\
\hline Aave_4391 & FliJ & -1.6543 & $1.31 \mathrm{E}-03$ & + \\
\hline Aave_4392 & FliI & -2.0475 & $5.74 \mathrm{E}-06$ & + \\
\hline Aave_4393 & FliH & -1.8625 & $2.70 \mathrm{E}-05$ & + \\
\hline Aave_4394 & FliG & -1.3578 & $3.17 \mathrm{E}-03$ & - \\
\hline Aave_4395 & FliF & -1.4969 & $3.69 \mathrm{E}-03$ & + \\
\hline Aave_4396 & FliE & -1.4713 & $1.38 \mathrm{E}-03$ & - \\
\hline Aave_4397 & FliT & -1.5382 & 4.61E-04 & + \\
\hline Aave_4398 & FliS & -1.9045 & $8.83 \mathrm{E}-06$ & + \\
\hline Aave_4399 & FliD & -1.4676 & 5.84E-04 & + \\
\hline Aave_4400 & FliC & -1.7655 & $6.32 \mathrm{E}-03$ & + \\
\hline Aave_4401 & FliC & -1.7441 & $9.88 \mathrm{E}-05$ & + \\
\hline Aave_4413 & FlhA & -2.4171 & $9.67 \mathrm{E}-09$ & + \\
\hline Aave_4416 & FliA & -1.4553 & $9.71 \mathrm{E}-04$ & + \\
\hline Aave_4418 & FlgM & -1.6623 & $9.88 \mathrm{E}-05$ & + \\
\hline Aave_4420 & FlgB & -1.9958 & $8.57 \mathrm{E}-05$ & + \\
\hline Aave_4421 & $\mathrm{FlgC}$ & -2.2891 & $2.49 \mathrm{E}-06$ & + \\
\hline Aave_4422 & FlgD & -2.3236 & $1.46 \mathrm{E}-05$ & + \\
\hline Aave_4425 & FlgG & -2.7728 & $2.30 \mathrm{E}-10$ & - \\
\hline Aave_4426 & $\mathrm{FlgH}$ & -2.6785 & $4.75 \mathrm{E}-10$ & + \\
\hline Aave_4428 & FlgI & -1.9582 & $3.48 \mathrm{E}-05$ & + \\
\hline Aave_4429 & FlgJ & -2.4272 & $2.20 \mathrm{E}-08$ & + \\
\hline Aave_4430 & FlgK & -2.414 & $1.12 \mathrm{E}-08$ & + \\
\hline Aave_4431 & FlgL & -2.6884 & $1.15 \mathrm{E}-09$ & + \\
\hline Aave_4742 & $\begin{array}{l}\text { Flagellar } \\
\text { basal body } \\
\text { rod protein }\end{array}$ & -1.3296 & $6.33 \mathrm{E}-03$ & - \\
\hline Aave_2005 & FlhC & -2.1672 & $4.09 \mathrm{E}-02$ & + \\
\hline Aave_3554 & PilV & -1.0804 & $2.70 \mathrm{E}-02$ & - \\
\hline Aave_0999 & PilQ & -1.0871 & $2.04 \mathrm{E}-02$ & - \\
\hline Aave_4153 & PilN & 1.2638 & $7.96 \mathrm{E}-03$ & - \\
\hline
\end{tabular}

pathogen Brucella melitensis (Rambow-Larsen et al. 2008). VjbR was found to regulate the virB operon and flagellar genes, while BlxR regulates the expression of a number of genes encoding the virB operon and flagella (Delrue et al. 2005; Rambow-Larsen et al. 2008). In the present study, AclR and AcrR both regulate the virulence, motility, and biofilm formation of $A$. citrulli. In our transcriptome analysis, the expression level of $a c r R$ was not significantly changed in the $a c l R$ mutant strain, and the expression level of aclR was not significantly changed in the $a c r R$ mutant strain either (Guan et al. 2020), suggesting that AclR and AcrR may be involved in regulating networks independent of each other. Additionally, genes downregulated by $a c l R$ are mainly involved in bacterial motility and flagellar assembly, while genes downregulated by $a c r R$ are mainly involved in motility and metabolism, consistent with the absence of motility and an increase in in vivo growth ability of $\Delta a c r R$. Taken together, A. citrulli may utilize two LuxR-type transcriptional regulators to regulate its virulence, motility, and biofilm formation, although via different pathways.

In summary, the $a c l R$ gene contributes to the virulence, motility, and biofilm formation of the A. citrulli Aac-5 strain and may play a role in regulating the motility-biofilm transition. Additionally, our transcriptomic analysis revealed that $a c l R$ repressed the expression of genes associated with flagellar assembly, swimming, and twitching motility, while promoting the expression of genes involved in lipopolysaccharide biosynthesis, amino sugar and nucleotide sugar metabolism, and oxidative phosphorylation, which were not significantly changed when AcrR was eliminated in the Aac-5 strain of A. citrulli (Guan et al. 2020), suggesting different regulatory mechanisms for AclR and AcrR. Our results not only add to our knowledge on the functions of LuxR family transcriptional regulators but also facilitate the exploration of the regulatory networks modulated by LuxR-type regulators in A. citrulli. Considering that AclR harbors a response regulatory domain at the $\mathrm{N}$ terminus, we speculate that AclR may interact with other signals related to multiple biological functions in A. citrulli. Thus, if present, the signals remain completely unknown. Future research is needed to identify such signals and elucidate the molecular mechanisms underlying the regulation of A. citrulli by AclR for the development of effective control strategies to combat this important bacterial pathogen.

\section{MATERIALS AND METHODS}

\section{Bacterial strains, plasmids, growth conditions, and primer design.}

The bacterial strains and plasmids used in this study are listed in Table 1. A. citrulli strains were grown in $\mathrm{KB}$ broth or on a KA plate ( $\mathrm{KB}$ containing agar at $15 \mathrm{~g} /$ /iter) with appropriate antibiotics at $28^{\circ} \mathrm{C}$ in a growth chamber. Escherichia coli strains were grown in Luria-Bertani (LB) liquid or on an LB plate (LB containing agar at $15 \mathrm{~g} /$ liter) at $37^{\circ} \mathrm{C}$. Ampicillin (Ap) was applied at a concentration of $100 \mu \mathrm{g} \mathrm{ml}{ }^{-1}$, and $\mathrm{Km}$ and $\mathrm{Gm}$ were applied at $50 \mu \mathrm{g} \mathrm{ml}^{-1}$. The primer pair aclR-F/R was designed based on the aclR gene in the AAC00-1 genome (GenBank accession number CP000512.1), while primer pairs LaclR-F/R and RaclR-F/R were designed based on the upstream and downstream sequences of the $a c l R$ gene (Table 1). Primers $\mathrm{GmF} / \mathrm{R}$ were designed based on the Gm cassette (Table 1). All primers used in this study were designed using Primer 3.0. Antibiotics and materials for media were purchased from Jiangchen Ltd., Beijing, China.

\section{Construction of the $a c l R$ mutant and its complemented strain.}

The aclR gene deletion mutant was constructed by homologous double recombination, as previously described (Wang et al. 2016). Briefly, the upstream and downstream sequences of the 
$a c l R$ gene (550 and 555 bp in length, respectively) were amplified from the wild-type strain Aac-5 using the LaclR-F/LaclR-R and RaclR-F/RaclR-R primers (Table 1). The Gm cassette was amplified using the $\mathrm{GmF} / \mathrm{R}$ primer pair. Following confirmation by sequencing, the PCR fragments were digested with appropriate restriction enzymes and ligated into pK18mobsacB (Schäfer et al. 1994) to create the plasmid pK18-acrRGm (Table 2). The plasmid was then introduced into A. citrulli strain Aac-5 from E. coli DH5 $\alpha$ (Hanahan 1983) by triparental conjugation, using pRK600 as a helper plasmid to create the aclR mutant strain $\Delta a c l R$ (Table 2). Transconjugants were screened on KB supplemented with $10 \%$ sucrose and antibiotics (Ap and $\mathrm{Gm}$ ). The presence of the $\mathrm{Gm}$ cassette in the transconjugants was confirmed by PCR, and by sequencing the amplified PCR product using the primer pair $\mathrm{GmF} / \mathrm{GmR}$. The absence of the $a c l R$ gene in the transconjugants was confirmed by a lack of PCR product using the primer pair aclR-F/aclR-R (Table 1). All PCR assays contained $1 \mu \mathrm{l}$ of DNA template, $15 \mu \mathrm{l}$ of $2 \times$ Taq PCR Master mix (Tiangen, Beijing, China), and $1 \mu \mathrm{l}$ of each primer for a total reaction volume of $30 \mu \mathrm{l}$. The PCR conditions were $95^{\circ} \mathrm{C}$ for $3 \mathrm{~min}$; 30 cycles of $95^{\circ} \mathrm{C}$ for $30 \mathrm{~s}, 60^{\circ} \mathrm{C}$ for $30 \mathrm{~s}$, and $72^{\circ} \mathrm{C}$ for $90 \mathrm{~s}$; followed by $72^{\circ} \mathrm{C}$ for $10 \mathrm{~min}$.

To generate a $\Delta a c l R$ complementation strain, the $a c l R$ gene in Aac-5 was amplified using primers aclR-F and aclR-R (Table 1). The PCR product was digested with HindIII and BamHI, and cloned into pBBR1MCS-2 (Kovach et al. 1995) to generate pBBR-aclR, which was transferred into the mutant strain $\Delta a c l R$ by triparental conjugation (Table 2). The successful transconjugant $(\Delta a c l R-c)$ was identified through screening on $\mathrm{KB}$ (amended with Ap, Km, and $\mathrm{Gm}$ ) (Table 2). The identity of all obtained plasmids and A. citrulli strains were confirmed by PCR and DNA sequencing.

\section{Virulence assays.}

The virulence of the A. citrulli strains was assessed as previously described (Wang et al. 2016). Briefly, 3-week-old watermelon seedlings (Citrullus lanatus 'Jingxin\#6', provided by the Beijing Academy of Agriculture and Forestry Sciences, Beijing, China) were spray inoculated with $200 \mathrm{ml}$ of a cell suspension

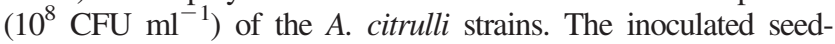
lings were grown at $28^{\circ} \mathrm{C}$ in a growth chamber with $90 \%$ relative humidity. The symptoms were evaluated 10 days postinoculation, and the DI was calculated according to the severity scale and formula described by Wang et al. (2016). Briefly, the severity of symptoms was classified as $0=$ no symptoms; $1=25 \%, 3=$ $50 \%, 5=75 \%$, and $7=100 \%$ necrosis of the leaves; or $9=$ complete death of the seedling. The DI was calculated based on the formula DI $=\sum[(A \times B) \times 100] /(C \times 9)$, where $A$ is the disease scale $(0,1,3,5,7$, or 9$), B$ is the number of seedlings at each level of the scale, and $C$ is the total number of seedlings for each treatment. For each $A$. citrulli strain, six watermelon seedlings in three pots were inoculated per experiment, and the experiment was repeated three times.

The ability of $A$. citrulli strains to grow in planta was determined in the cotyledons of 2-week-old watermelon seedlings (the same cultivar that was used in the virulence assay), using the method described Guan et al. (2020). Briefly, overnight cultures of $A$. citrulli strains were spun down at 5,000 rpm for $1 \mathrm{~min}$ in a microcentrifuge (Centrifuge 5430R; Eppendorf AG, Hamburg, Germany), the bacterial cells obtained were washed three times with sterile water, and the concentration was adjusted to $10^{4} \mathrm{CFU} \mathrm{ml} \mathrm{m}^{-1}$ with sterile water to prepare the bacterial inoculum. Each watermelon cotyledon was infiltrated with $1 \mathrm{ml}$ of inoculum using a sterile syringe. Six injected cotyledons, each inoculated with either the A. citrulli strain or water, were collected 1, 24, 48, 72, and 96 hai. One 3-mm disc from each cotyledon, and six discs in total, were collected and homogenized in $1 \mathrm{ml}$ of sterile water. The lysates were serially diluted with sterile water and plated on KA plates, which were then incubated at $28^{\circ} \mathrm{C}$ for $48 \mathrm{~h}$. Colonies on the $\mathrm{KA}$ plates were counted and used to quantify populations of $A$. citrulli strains growing in watermelon cotyledons. The experiment was repeated three times, with 30 repeats per treatment.

\section{Biofilm formation assays.}

The ability of $A$. citrulli strains to form biofilms was assessed qualitatively and quantitatively using glass flasks, as previously described (Wang et al. 2016). Briefly, $100 \mu \mathrm{l}$ of each cell suspension (optical density at $600 \mathrm{~nm}\left[\mathrm{OD}_{600}\right]=0.1$ ) was added to $10 \mathrm{ml}$ of liquid $\mathrm{KB}$ in a glass flask and incubated at $28^{\circ} \mathrm{C}$ without agitation. After slowly removing the liquid culture, the flasks were gently rinsed three times with sterile distilled water, then placed at $80^{\circ} \mathrm{C}$ in an oven (Memmert, Schwabach, Germany) for $30 \mathrm{~min}$ to fix the biofilm. After fixation, the biofilms on the inner surface of the glass flasks were stained with $2 \mathrm{ml}$ of $0.1 \%$ (wt/vol) crystal violet for $2 \mathrm{~h}$. To quantify biofilm formation, the stained biofilm was solubilized in $5 \mathrm{ml}$ of anhydrous ethanol for $12 \mathrm{~h}$, and the $\mathrm{OD}_{580}$ of the stained suspension was measured with a spectrophotometer (Biophotometer; Eppendorf, Hamburg, Germany). Three biological replicates were performed per A. citrulli strain per experiment, and the experiment was repeated three times.

\section{Growth ability assay.}

For measuring growth ability of Aac-5, $\Delta a c l R$, and $\Delta a c l R-c$ strains of $A$. citrulli, a $2-\mu$ l cell suspension of each strain at $\mathrm{OD}_{600}$ of 0.3 was diluted 100 -fold with $198 \mu \mathrm{l}$ of liquid $\mathrm{KB}$ medium in the well of a 96-well plate. The plate was incubated at $28^{\circ} \mathrm{C}$ with shaking at $220 \mathrm{rpm}$, and the $\mathrm{OD}_{600}$ was measured every $2 \mathrm{~h}$ for $72 \mathrm{~h}$ in a Bioscreen C chamber (FP-1100-C; Oy Growth Curves Ab Ltd., Helsinki, Finland).

\section{Twitching motility assays.}

Suspensions $\left(10 \mu \mathrm{l}\right.$ each at $\left.\mathrm{OD}_{600}=1\right)$ of A. citrulli strains were placed on KA plus Ap plates and incubated for $72 \mathrm{~h}$, and twitching motility was visualized using an upright microscope (Olympus BX63), as previously described (Bahar et al. 2009). Colonies with twitching motility were characterized by the formation of corrugated trajectories or halos around the colonies. Nine plates were inoculated per strain per experiment, and the experiment was repeated three times.

\section{Swimming motility assay and flagella observation by transmission electron microscopy.}

The swimming motility of each $A$. citrulli strain was determined using the methods described by Wang et al. (2016). A. citrulli strains were grown in $\mathrm{KB}$, and their $\mathrm{OD}_{600}$ was adjusted to 0.6 . Bacterial suspensions ( $10 \mu \mathrm{l}$ each) were incubated on the center of a basal medium plate with $0.3 \%$ agar for $36 \mathrm{~h}$ at $28^{\circ} \mathrm{C}$. The diameter of the colony on each plate was measured. In total, nine plates were inoculated per strain per experiment, and the experiment was repeated three times.

To observe flagella, each $A$. citrulli strain was grown on the basal medium for $36 \mathrm{~h}, 10 \mu \mathrm{l}$ of sterile water was placed on top of each colony for $2 \mathrm{~min}$, and a 200-mesh formvar-coated copper grid was placed on top of each water drop for $1 \mathrm{~min}$. The copper grids were negatively stained with $1 \%$ uranyl acetate three times for $30 \mathrm{~s}$ each. Transmission electron microscopy was used to observe the polar flagella of each A. citrulli.

\section{RNA isolation and qRT-PCR analysis of gene expression.}

RNA was isolated from $A$. citrulli strains using the method described by Wang et al. (2016). Bacterial cells of A. citrulli strains were grown in $\mathrm{KB}$ at $28^{\circ} \mathrm{C}$ overnight to an $\mathrm{OD}_{600}$ of 0.8 , 
then washed twice with sterilized water and used for RNA extraction. RNA was extracted according to the instructions provided with the RNeasy Mini Kit (Qiagen, Hilden, Germany). The RNA was then reverse-transcribed using a QuantiNova Reverse Transcription Kit (Qiagen), according to the manufacturer's instructions. RT-qPCR analysis was performed using the cDNA as template with SYBR Green and appropriate primers (Supplementary Table S2). The final volume of each qPCR was $10 \mu \mathrm{l}$, with $1 \mu \mathrm{l}$ of total cDNA, $1 \mu \mathrm{l}$ of forward or reverse primers, $5 \mu \mathrm{l}$ of SuperReal SYBR Green PreMix (Tiangen, Beijing, China), and $2 \mu \mathrm{l}$ of double-distilled water. Cycling conditions were $95^{\circ} \mathrm{C}$ for $15 \mathrm{~min}$, then 40 cycles of $95^{\circ} \mathrm{C}$ for $10 \mathrm{~s}$ and $60^{\circ} \mathrm{C}$ for $30 \mathrm{~s}$. Relative gene expression was determined as previously described using the gylA gene as the internal control (Wang et al. 2016). Three biological replicates were used per experiment, and the experiment was repeated three times.

\section{RNA-seq and data analysis.}

RNA $(3 \mu \mathrm{g})$ from each $A$. citrulli strain was used as the input material to prepare RNA samples. The RNA sequencing libraries were constructed and sequenced commercially by Novogene Co., Ltd. using the NEBNext Ultra RNA Library Prep Kit for Illumina (NEB). The libraries were constructed and sequenced as previously described (Guan et al. 2020).

The sequencing data were analyzed commercially by Novogene Co., Ltd. Differential gene expression between the wild-type strain Aac-5 and the $a c l R$ mutant strain $\Delta$ aclR (three biological replicates per strain) was analyzed using the DESeq $\mathrm{R}$ package (v. 1.10.1). Genes with an adjusted $P$ value $<0.05$ identified by DESeq were considered to be differentially expressed (Pan et al. 2018). GO and KEGG pathway enrichments were performed as previously described (Guan et al. 2020).

\section{Statistical analysis.}

Statistical analysis was performed using the Student's $t$ test in Excel 2010 software (Microsoft Inc.). Differences were considered statistically significant at $P$ value at either the 5 or $1 \%$ level.

\section{LITERATURE CITED}

Ayers, M., Sampaleanu, L. M., Tammam, S., Koo, J., Harvey, H., Howell, P. L., and Burrows, L. L. 2009. PilM/N/O/P proteins form an inner membrane complex that affects the stability of the Pseudomonas aeruginosa type IV pilus secretin. J. Mol. Biol. 394:128-142.

Bahar, O., and Burdman, S. 2010. Bacterial fruit blotch: A threat to the cucurbit industry. Isr. J. Plant Sci. 58:19-31.

Bahar, O., Goffer, T., and Burdman, S. 2009. Type IV pili are required for virulence, twitching motility, and biofilm formation of Acidovorax avenae subsp. Citrulli. Mol. Plant-Microbe Interact. 22:909-920.

Bahar, O., Levi, N., and Burdman, S. 2011. The cucurbit pathogenic bacterium Acidovorax citrulli requires a polar flagellum for full virulence before and after host-tissue penetration. Mol. Plant-Microbe Interact. 24:1040-1050.

Ball, A. S., Chaparian, R. R., and van Kessel, J. C. 2017. Quorum sensing gene regulation by LuxR/HapR master regulators in Vibrios. J. Bacteriol. 199:e00105-17.

Burdman, S., Kots, N., Kritzman, G., and Kopelowitz, J. 2005. Molecular, physiological, and host-range characterization of Acidovorax avenae subsp. citrulli isolates from watermelon and melon in Israel. Plant Dis. 89:1339-1347.

Burkhardt, J., Vonck, J., and Averhoff, B. 2011. Structure and function of PilQ, a secretin of the DNA transporter from the thermophilic bacterium Thermus thermophilus HB27. J. Biol. Chem. 286:9977-9984.

Chen, J., and Xie, J. 2011. Role and regulation of bacterial LuxR-like regulators. J. Cell. Biochem. 112:2694-2702.

Chen, T., Qian, G.-L., Yang, X.-L., Ma, J.-Y., Hu, B.-S., and Liu, F.-Q. 2009. Detection of a quorum sensing signal molecule of Acidovorax avenae subsp. citrulli and its regulation of pathogenicity. Chin. J. Agric. Biotechnol. 6:49-53.

Danhorn, T., and Fuqua, C. 2007. Biofilm formation by plant-associated bacteria. Annu. Rev. Microbiol. 61:401-422.
Delrue, R. M., Deschamps, C., Léonard, S., Nijskens, C., Danese, I., Schaus, J. M., Bonnot, S., Ferooz, J., Tibor, A., De Bolle, X., and Letesson, J. J. 2005. A quorum-sensing regulator controls expression of both the type IV secretion system and the flagellar apparatus of Brucella melitensis. Cell. Microbiol. 7:1151-1161.

Fan, J., Qian, G., Chen, T., Zhao, Y., Liu, F., Walcott, R. R., and Hu, B. 2011. The acyl-homoserine lactone (AHL)-type quorum sensing system affects growth rate, swimming motility and virulence in Acidovorax avenae subsp. citrulli. World J. Microbiol. Biotechnol. 27:11551166.

Fuqua, C., and Greenberg, E. P. 2002. Listening in on bacteria: Acylhomoserine lactone signalling. Nat. Rev. Mol. Cell Biol. 3:685-695.

Fuqua, C., Parsek, M. R., and Greenberg, E. P. 2001. Regulation of gene expression by cell-to-cell communication: Acyl-homoserine lactone quorum sensing. Annu. Rev. Genet. 35:439-468.

Fuqua, C., Winans, S. C., and Greenberg, E. P. 1996. Census and consensus in bacterial ecosystems: The LuxR-LuxI family of quorum-sensing transcriptional regulators. Annu. Rev. Microbiol. 50:727-751.

Giltner, C. L., Habash, M., and Burrows, L. L. 2010. Pseudomonas aeruginosa minor pilins are incorporated into type IV pili. J. Mol. Biol 398:444-461.

Guan, W., Wang, T., Huang, Q., Tian, E., Liu, B., Yang, Y., and Zhao, T. 2020. A LuxR-type regulator, AcrR, regulates flagellar assembly and contributes to virulence, motility, biofilm formation, and growth ability of Acidovorax citrulli. Mol. Plant Pathol. 21:489-501.

Guttenplan, S. B., Blair, K. M., and Kearns, D. B. 2010. The EpsE flagellar clutch is bifunctional and synergizes with EPS biosynthesis to promote Bacillus subtilis biofilm formation. PLoS Genet. 6:e1001243.

Guttenplan, S. B., and Kearns, D. B. 2013. Regulation of flagellar motility during biofilm formation. FEMS Microbiol. Rev. 37:849-871.

Hanahan, D. 1983. Studies on transformation of Escherichia coli with plasmids. J. Mol. Biol. 166:557-580.

Hickman, J. W., and Harwood, C. S. 2008. Identification of FleQ from Pseudomonas aeruginosa as a c-di-GMP-responsive transcription factor. Mol. Microbiol. 69:376-389.

Johnson, K. L., and Walcott, R. R. 2013. Quorum sensing contributes to seed-to-seedling transmission of Acidovorax citrulli on watermelon. J. Phytopathol. 161:562-573.

Kovach, M. E., Elzer, P. H., Hill, D. S., Robertson, G. T., Farris, M. A., Roop, R. M., 2nd, and Peterson, K. M. 1995. Four new derivatives of the broad-host-range cloning vector pBBR1MCS, carrying different antibiotic-resistance cassettes. Gene 166:175-176.

Lemon, K. P., Higgins, D. E., and Kolter, R. 2007. Flagellar motility is critical for Listeria monocytogenes biofilm formation. J. Bacteriol. 189:4418-4424.

Li, Y., and Li, H. 2014. Type IV pili of Acidithiobacillus ferrooxidans can transfer electrons from extracellular electron donors. J. Basic Microbiol. 54:226-231

Macnab, R. M. 2003. How bacteria assemble flagella. Annu. Rev. Microbiol. 57:77-100.

Narulita, E., Addy, H. S., Kawasaki, T., Fujie, M., and Yamada, T. 2016. The involvement of the PilQ secretin of type IV pili in phage infection in Ralstonia solanacearum. Biochem. Biophys. Res. Commun. 469:868-872.

Nieto, V., Kroken, A. R., Grosser, M. R., Smith, B. E., Metruccio, M. M. E., Hagan, P., Hallsten, M. E., Evans, D. J., and Fleiszig, S. M. J. 2019. Type IV pili can mediate bacterial motility within epithelial cells. MBio 10:e02880-18.

Pan, H., Pierson, L. S., 3rd, and Pierson, E. A. 2020. PcsR2 is a LuxRtype regulator that is upregulated on wheat roots and is unique to Pseudomonas chlororaphis. Front. Microbiol. 11:2731.

Pan, Y., Liang, F., Li, R.-J., and Qian, W. 2018. MarR-family transcription factor HpaR controls expression of the vgrR-vgrS operon of Xanthomonas campestris pv. campestris. Mol. Plant-Microbe Interact. 31:299-310.

Patankar, A. V., and González, J. E. 2009. An orphan LuxR homolog of Sinorhizobium meliloti affects stress adaptation and competition for nodulation. Appl. Environ. Microbiol. 75:946-955.

Rambow-Larsen, A. A., Rajashekara, G., Petersen, E., and Splitter, G. 2008. Putative quorum-sensing regulator BlxR of Brucella melitensis regulates virulence factors including the type IV secretion system and flagella. J. Bacteriol. 190:3274-3282.

Santos, C. L., Correia-Neves, M., Moradas-Ferreira, P., and Mendes, M. V. 2012. A walk into the LuxR regulators of Actinobacteria: Phylogenomic distribution and functional diversity. PLoS One 7:e46758.

Schäfer, A., Tauch, A., Jäger, W., Kalinowski, J., Thierbach, G., and Pühler, A. 1994. Small mobilizable multi-purpose cloning vectors derived from the Escherichia coli plasmids pK18 and pK19: Selection 
of defined deletions in the chromosome of Corynebacterium glutamicum. Gene 145:69-73.

Singer, H. M., Erhardt, M., and Hughes, K. T. 2013. RflM functions as a transcriptional repressor in the autogenous control of the Salmonella Flagellar master operon flhDC. J. Bacteriol. 195:4274-4282.

Subramanian, S., and Kearns, D. B. 2019. Functional regulators of bacterial flagella. Annu. Rev. Microbiol. 73:225-246.

Talà, L., Fineberg, A., Kukura, P., and Persat, A. 2019. Pseudomonas aeruginosa orchestrates twitching motility by sequential control of type IV pili movements. Nat. Microbiol. 4:774-780.

Tammam, S., Sampaleanu, L. M., Koo, J., Sundaram, P., Ayers, M., Chong, P. A., Forman-Kay, J. D., Burrows, L. L., and Howell, P. L. 2011. Characterization of the PilN, PilO and PilP type IVa pilus subcomplex. Mol. Microbiol. 82:1496-1514.

Tsai, C.-S., and Winans, S. C. 2010. LuxR-type quorum-sensing regulators that are detached from common scents. Mol. Microbiol. 77: 1072-1082.

van Kessel, J. C., Ulrich, L. E., Zhulin, I. B., and Bassler, B. L. 2013. Analysis of activator and repressor functions reveals the requirements for transcriptional control by LuxR, the master regulator of quorum sensing in Vibrio harveyi. MBio 4:e0378-13.

Vuong, C., Kocianova, S., Voyich, J. M., Yao, Y., Fischer, E. R., DeLeo, F. R., and Otto, M. 2004. A crucial role for exopolysaccharide modification in bacterial biofilm formation, immune evasion, and virulence. J. Biol. Chem. 279:54881-54886.
Walcott, R. R., Fessehaie, A., and Castro, A. C. 2004. Differences in pathogenicity between two genetically distinct groups of Acidovorax avenae subsp. citrulli on cucurbit hosts. J. Phytopathol. 152:277-285.

Wang, T., Guan, W., Huang, Q., Yang, Y., Yan, W., Sun, B., and Zhao, T. 2016. Quorum-sensing contributes to virulence, twitching motility, seed attachment and biofilm formation in the wild type strain Aac-5 of Acidovorax citrulli. Microb. Pathog. 100:133-140.

Waters, C. M., Lu, W., Rabinowitz, J. D., and Bassler, B. L. 2008. Quorum sensing controls biofilm formation in Vibrio cholerae through modulation of cyclic di-GMP levels and repression of vpsT. J. Bacteriol. 190:2527-2536.

Yan, S., Yang, Y., Wang, T., Zhao, T., and Schaad, N. W. 2013. Genetic diversity analysis of Acidovorax citrulli in China. Eur. J. Plant Pathol. 136:171-181.

Yildiz, F. H., Liu, X. S., Heydorn, A., and Schoolnik, G. K. 2004. Molecular analysis of rugosity in a Vibrio cholerae O1 El Tor phase variant. Mol. Microbiol. 53:497-515.

Zhang, A., Zhang, X., Wu, L., Yu, C., Qiao, P., Yang, Y., Guan, W., and Zhao, T. 2017. Construction of chemotaxis and flagella gene double mutant $\Delta c h e A \Delta f l i C$ and its functional analysis in Acidovorax citrulli. Chin. J. Agric. Biotechnol. 25:1838-1850.

Zhu, J., and Mekalanos, J. J. 2003. Quorum sensing-dependent biofilms enhance colonization in Vibrio cholerae. Dev. Cell 5:647-656.

Zhu, J., Miller, M. B., Vance, R. E., Dziejman, M., Bassler, B. L., and Mekalanos, J. J. 2002. Quorum-sensing regulators control virulence gene expression in Vibrio cholerae. Proc. Natl. Acad. Sci. U.S.A. 99:3129-3134. 